This item was submitted to Loughborough's Research Repository by the author.

Items in Figshare are protected by copyright, with all rights reserved, unless otherwise indicated.

\title{
Is the economic crisis affecting birth outcome in Spain? Evaluation of temporal trend in underweight at birth (2003-2012)
}

PLEASE CITE THE PUBLISHED VERSION

http://dx.doi.org/10.3109/03014460.2015.1131847

PUBLISHER

(C) Taylor and Francis

\section{VERSION}

AM (Accepted Manuscript)

\section{PUBLISHER STATEMENT}

This work is made available according to the conditions of the Creative Commons Attribution-NonCommercialNoDerivatives 4.0 International (CC BY-NC-ND 4.0) licence. Full details of this licence are available at: https://creativecommons.org/licenses/by-nc-nd/4.0/

\section{LICENCE}

CC BY-NC-ND 4.0

\section{REPOSITORY RECORD}

Varea, Carlos, Jose Manuel Teran, Cristina Bernis, Barry Bogin, and Antonio Gonzalez-Gonzalez. 2019. "Is the Economic Crisis Affecting Birth Outcome in Spain? Evaluation of Temporal Trend in Underweight at Birth (2003-2012)". figshare. https://hdl.handle.net/2134/20884. 
Is the economic crisis affecting birth outcome in Spain? Evaluation of temporal trend in underweight at birth (2003-2012)

\begin{abstract}
Background: There is a growing evidence of the impact of the current European economic crisis on health. In Spain since 2008 there have been increasing levels of impoverishment and inequality, and important cuts in social services, including per capita spending on healthcare.
\end{abstract}

Aim: The objective is to evaluate the impact of the economic crisis on underweight at birth in Spain.

Method: Trends in underweight at birth were examined between 2003 and 2012. Underweight at birth is defined as a singleton, term neonatal weight lesser than -2 SD from the median weight at birth for each sex estimated by the WHO Standard Growth Reference. With this criterion and with data from the Statistical Bulletin of Childbirth, 2 933485 live births born to Spanish mothers have been analysed. Descriptive analysis, seasonal decomposition analysis and crude and adjusted logistic regression including individual maternal and foetal variables as well as exogenous economic indicators have been performed.

Results and conclusions: Results demonstrate a significant increase in the prevalence of underweight at birth as from 2008. All maternal-foetal categories were affected, including those which showed the lowest prevalence before the crisis. In the full adjusted logistic regression, year-on-year GDP per capita remains predictive on underweight at birth risk, in such a way that the fall in GDP between 2007 and 2012 determined an increase of the OR of underweight at birth by 6.63\%. Previous trends in maternal socio-demographic profile and a direct impact of the crisis are discussed to explain the trends described. 


\section{Introduction}

WHO established in 2006 that optimal foetal development should be considered an essential factor in social development and should be seen as an integral aspect of societal development (WHO, 2006a). Optimum foetal development has been defined (WHO, 2006a) as the state at birth which guarantees the survival of the neonate and an adequate development throughout the neonatal transition and infancy, such that there are no negative effects on the individual's life-course. The conditions which guarantee the optimal foetal development include all the maternal and environmental conditions which allow "the potential mother to be in a good state of physical and emotional health both prior to and during her pregnancy” (WHO, 2006a: 10). Weight at birth, together with foetal and neonatal viability and gestational age, is an important indicator for the quality of foetal development and an excellent predictor for immediate morbiditymortality and health throughout the life course (McIntire et al., 1999; Barker et al., 2002; Gluckman et al., 2008). Weight at birth is a complex phenotype resulting from the interaction between maternal, paternal and foetal genetics, epigenetics, and the environment (Lampl et al., 2010). However, the persistence of socioeconomic and health inequalities even in developed countries (in education, employment and resources, lifestyles, nutrition and healthcare access, hygienic and environmental conditions) continues to determine clear differences in perinatal health indicators (Rutter and Quine, 1990; Kogan, 1995; Kramer et al., 2000; Spencer, 2003; Wood, 2003; Aizer and Currie, 2014), differences that may become wider in periods of economic recession.

The financial crisis that has been affecting the global economy since the summer of 2007 has no precedent in post-war European social and economic history (Van den Noord and Székely, 2011). Recent findings reveal the immediate impact of the economic crisis on health inequality, on changes in healthcare systems and on specific aspects of population health in Europe (Cooper, 2011; Karanikolos et al., 2013; Stuckler et al., 2009; WHO, 2013), although Ásgeirsdóttir et al. (2014) concluded that the economic crisis may also lead to a reduction in health compromising behaviours.

Spain is among those European countries most directly affected by the international financial crisis, the so-called "stressed countries" (in addition to Spain: Italy, Greece, 
Ireland, Portugal and Slovenia among the EU-28 members). The Spanish population is suffering increasing levels of impoverishment and inequality (EUROSTAT, 2014; OECD, 2014, 2015). The Spanish government has confronted the crisis with a severe programme of labour reforms and cuts in social services, including per capita spending on healthcare since 2009 (Legido-Quigley et al., 2013) that is deeply affecting the social determinants of health in Spain (Borrell et al., 2014). At the same time, some regional governments have imposed additional budget cuts, which have led to an unprecedented increase in territorial disparities on social protection systems (Fundación BBVA, 2015). According to official figures and latest available data (INE, 2015; Eurostat, 2015), in the first trimester of 2015 Spain registered the second highest (after Greece) unemployment rate among the EU-28 countries (23.8\%), more than three times greater than the OECD average (OECD, 2015). Spain is among the five EU-28 countries with the highest income disparities, with a Gini coefficient of 34.7 in 2014. The AROPE (people AtRisk-Of Poverty or Social Exclusion) rate stood at 29.2\% in 2014 (five points higher than the EU average), affecting over 13.6 million people. By age group, the highest rate of AROPE (35.4\%) corresponds to the less than 16 years old group, as UNICEF (2014) emphasises. The AROPE rate refers to the situation of people either at risk of poverty, or severely materially deprived or living in a household with a very low work intensity. In Spain the relevant increase of the AROPE rate in the period 2009-2013 was due mainly to the third component of this indicator, the growth of households with low density of work which had more than doubled between 2009 and 2013 (Llano-Ortiz, 2015). In 2015 one in ten households (1.8 millions) had all work-capable members unemployed, always according to official information. The social situation continues to deteriorate despite recent macroeconomic improvement.

According to official figures (Ministerio de Hacienda y Administraciones Públicas. 2015), reduction in public health budgets was 16.5\% (10 000 million euros) between 2009 and 2013. Spanish health care professionals perceived that quality of health care had become worse and health outcomes had deteriorated since the beginning of the crisis as a result of austerity measures and restrictions introduced on the universal coverage and free access principles (Cervero-Liceras et al., 2015). The impact of the crisis on different aspects of health (mental health in particular) and on high-risk sectors of the Spanish population (such as immigrants) has already been well documented (Agudelo-Suárez et al., 2013; Gili et al., 2013; Barbaglia et al., 2014; Bartoll et al., 2014; Robert et al., 2014). As in other European countries (De Vogli et al., 2013), the 
economic crisis has already been associated with a relative increase in suicides (LópezBernal et al., 2013; Miret et al., 2014), as well as with a widening in socioeconomic inequalities in mortality (Maynou et al., 2014). Local studies confirm a dramatic increase in infant and child poverty and malnutrition since the beginning of the economic crisis determined by the worsening of family living conditions and basic services restrictions (Rajmil et al., 2013).

The impact of the economic crisis on pregnant women and birth outcome is less well studied. Recent research carried out in European countries particularly hard hit by the crisis (Ireland and Greece) has started to detect some evidence of a negative impact of recession on foetal development (Carolan-Olah and Barry, 2014; Vlachadis and Kornarou, 2013). However, confirmation of the negative impact of the economic crisis on foetal development is complicated by the fact that negative trends of birth outcome indicators were detected in European countries during the decade of sustained economic growth preceding the current crisis, which have been explained as the consequences of changes in the profile of the mothers and increasing obstetric intervention rates (EUROPERISTAT Project with SCPE and EUROCAT, 2013). In this context, throughout the two decades prior to the economic crisis Spain registered the greatest increase in low birth weight (LBW, births with a birth weight under 2,500 g) among the European countries (OECD, 2012), with no parallel increase in preterm births (babies born alive before 37 weeks of pregnancy), as occurred in other countries (Zeitlin et al., 2013). At the same time, a substantial reduction in late foetal and very early infant deaths (less than 24 hours) was achieved (Ministerio de Sanidad, Servicios Sociales e Igualdad, 2012). Bernis and Varea (2013) described a decrease in mean birth weight both in single and multiple births of Spanish mothers since 1996, followed by a slight recovery in the years preceding the economic crisis, as confirmed by Fuster et al. (2013). Despite the fact that these trends can complicate the analysis and interpretation of a possible negative impact of the economic crisis on birth outcomes in Spain, new data from recent analysis support this possibility. Juárez et al. (2014) showed increased inequalities in birth outcome in Andalusia, according to maternal education over the first years of the economic crisis.

Following this preliminary evidence, the hypothesis of this paper is that the economic crisis is having a negative impact on birth outcome in Spain which cannot be merely explained as a continuation of the birth weight trends described during the previous 
years of economic growth. This potential impact of the economic crisis on pregnant women and birth outcome may come about as a combination of maternal and environmental factors at individual, family and community levels through a reduction in material resources, deteriorating environmental conditions and increased psycho-social stress (Zilko, 2010).

\section{Material ad methods}

An unambiguous definition of normal foetal growth remains a challenge (Zhang et al., 2012). Low birth weight (LBW, less than 2.500 g, all gestational ages and both sexes considered) is the most used indicator of perinatal health, as it is relatively easy to measure and there are reliable international references. However, the use of LBW has some limitations, as birth weight is determined both by gestational age and the rate of foetal growth (Wollman, 1998; Kramer et al, 2000; Datta Gupta et al., 2013). As growth is a progressive process, an infant may weigh less than $2500 \mathrm{~g}$ at birth either because he/she is born too early (preterm birth) or because he/she was small for his/her gestational age, which is used as a proxy for intrauterine growth restriction. As Kramer (1987) indicated, the determinants and health consequences of gestational age (prematurity) are quite different from those of foetal growth (intrauterine growth restriction, IUGR).

To avoid these difficulties this study proposes the use of the WHO Child Growth Standards (WHO, 2006b) for evaluating foetal growth through the variable underweight at birth. The WHO Standards established in 2006 by WHO Multicentre Growth Reference Study Group have been adopted by Spain, among more than one hundred countries (de Onís et al., 2012). The WHO Standards consider underweight at birth those neonates whose weight is -2 SD from the median weight at birth for each sex, in single births with a gestational age from 37 to 41 complete weeks. According to the United States National Institutes of Child Health \& Human Development (Spong, 2013 this gestational age range includes 'early term' (37 and 38 weeks and 6 days), 'full term' (39-40 weeks and 6 days) and 'late term' births (41-41 weeks 6 days). Underweight at birth for term neonates corresponds to under $3^{\text {rd }}$ percentile, which is a suitable epidemiological indicator of increased risk of morbid-mortality at birth and throughout the life-cycle which derives directly from IUGR (Kramer, 1987). It also allows the assessment of secular trends and intra-population variability in birth weight 
(Wilcox, 2001) according to a recognised international reference, a methodological matter of concern until now (Goldenberg et al., 1997). Furthermore, the cut-off points for underweight at term birth established are different for each sex (2500 gr for male neonates and 2400 for females), allowing for an evaluation of sex differences in response to maternal conditions and socioeconomic changes affecting foetal development (Stinson, 1985).

Data analysed in this study came from the Spanish Statistical Bulletin of Childbirth (BEP, Boletín Estadístico de Parto), the compulsory civil registration of all births whatever the nationality or legal status of residence of the parents. Validation studies have concluded that data provided by the Spanish birth certificate are quite reliable when compared with hospital birth statistics (Juárez et al., 2012; Río et al., 2010), although misreporting is significantly higher among immigrants, particularly in gestational age and birth weight. The three main groups of immigrant mothers in Spain (Latin-American, Maghreb, and Eastern European women) have very different lifestyles, cultural practices, nutritional behaviour and genetic heritage, requiring a specific analysis on differences in birth outcome compared with Spanish mothers. Furthermore, previous analyses (Varea et al, 2012; Bernis and Varea, 2013; Bernis et al., 2013) have confirmed that immigrant mothers maintained better trends in birth weight (and a lower prevalence and risk of LBW) than the Spanish mothers despite having higher rates of preterm deliveries. Due to these reasons, immigrant mothers and their newborns have been excluded from the present analysis. However, it should be mentioned that $3.3 \%$ of the Spanish mothers were originally immigrants that obtained Spanish citizenship in the period 2007-2012 (previous to 2007 there is no information on when the mother obtained Spanish nationality, at birth or, as immigrants, later).

The new variable underweight at birth was created for term (37-41 weeks) neonates for each sex born in the period 2003-2012 from the original variables gestational age and birth weight. According to this criterion, analysis in this study corresponds to 2933485 single, term live births born to Spanish mothers in the period 2003-2012 (1 753789 neonates were excluded).

A preliminary seasonal decomposition analysis on total prevalence of underweight at birth by month during the period 2003-2012 was performed in order to detect any temporal trend in the data. No systematic seasonal variations were detected. Trends in 
the prevalence of underweight at birth by month and year of birth both for the original series and for the smoothed trend-cycle components and seasonally adjusted series are shown.

Second, we carried out a descriptive analysis of the prevalence of underweight at birth during the period of study according to maternal and foetal characteristics. Maternal and foetal independent variables at the individual level analysed were those available in both the previous (1996-2006) and the current (2007 onwards) Spanish birth registration form: maternal age (which has been categorized into $\leq 20,21-27,28-34$ and $>34$ years old groups), maternal occupation (professionals, administrative employees, Service sector workers, Primary and Secondary sectors skilled workers and members of the Armed Forces, unskilled workers, students, and housewives), size of the municipality of maternal residence (four categories according to number of inhabitants plus provincial capitals), parity (primiparous or multiparous) and sex of the newborn. Secular trends of the prevalence of underweight at birth, and by maternal and foetal categories were also evaluated

Finally, the possible impact of the economic recession on birth outcome was analysed by means of several logistic regression analyses. Three economic indicators available for the period 2003-2012 have been selected as exogenous, independent predictors at the national and household regional levels on underweight at birth risk: year-on-year Gross Domestic Product (GDP) per capita, year-on-year Gross Disposable Income of Households per capita by Autonomous Communities and Gini coefficient. The annual and regional values of these three macroeconomic variables have been associated to each birth. Year-on-year GDP per capita is the most direct indicator of the global trends of the economic activity in the country and adequately summarizes alternative activity indicators proposed (Ministerio de Economía y Hacienda, 2007). Year-on-year Gross Disposable Income of Households per capita is recommended by Eurostat as the best measurement of standard of living and monetary well-being of families. Evaluated at the regional level-by Autonomous Communities, the 17 first-level political and administrative division of Spain-this indicator allows us to consider previous territorial socioeconomic disparities as well as the differential impact of the economic crisis by regions since 2008 (Méndez et al., 2015). Finally, Gini coefficient is the most commonly used indicator of intra-population income inequality. 
The lack of monthly data for these economic indicators in Spain does not allow us to perform an analysis of the timing of exposure to economic fluctuations by trimesters of pregnancy as Bozzoli and Quinta-Domeque (2014) recommended. Consequently, annual values of these economic variables have been assigned to each baby born in a given year. Analyses described below have been duplicated for month (year) of conception, and new variables calculated from month of birth and gestational age. No significant differences have been found.

Two logistic binomial regressions have been performed to evaluate the impact of the economic crisis on underweight at birth: (a) three crude models for each economic variable on risk of being born with underweight at birth; and (b) an adjusted model including the three economic variables and as covariates the maternal and foetal variables indicated above as well as - to improve the model-year of birth, paternal occupation, and gestational age (continuous). According to the previous descriptive analysis, reference category in each covariate was the group with the lower prevalence of underweight at birth. Previous univariate and bivariate logistic regressions performed confirmed that all independent variables were predictors of underweight at birth risk, and that there were no significant interactions on underweight at birth risk among them.

\section{Results}

Figure 1 shows the trend in the prevalence of underweight at birth by month and year of birth, both for the original series and for the estimated trend component on a seasonally adjusted series (see Table I in the Appendix). Both series show a sharp increase between 2007 and 2008-four times higher than between 2006 and 2007. The global prevalence of underweight at birth increased $18.18 \%$ between the periods before and after the economic crisis, from $2.21 \%$ in $2003-2007$ to $2.61 \%$ in $2008-2012(\chi 2=473.894$, $\mathrm{df}=1$, $\mathrm{p}<0.001)$.

\section{[FIGURE 1]}

Table I describes the analysed population according to selected maternal and newborn characteristics for the period 2003-2012 and the prevalence of underweight at birth for each category. Spanish mothers were predominantly highly qualified professionals and administrative employees (almost half), over half between 28-34 years old and one third 
over 34 years old, urban dwellers (fewer than 20\% were living in towns with less than 10000 inhabitants) and primiparous (55.42\%). The highest rates of underweight at birth were among neonates of mothers under 20 years old (3.39\%), with less qualified jobs and housewives (2.79 and 2.78\%, respectively), living in cities of over 100000 inhabitants (2.62\%), and primiparous (2.72\%). Male newborns showed higher prevalence of underweight at birth than females (2.51 and 2.29\%, respectively). Figures 2 to 6 (and Table I in the Appendix) show the temporal trend in the prevalence of underweight at birth in neonates for all these categories of maternal and foetal variables selected. There are two considerations of interest. First, the prevalence of underweight at birth increased in all categories with much greater intensity from 2008 than in the preceding years, particularly during the worst period of the economic crisis (2009 and 2010). Thus, the prevalence of underweight at birth increased in 2011 to over $4 \%$ in mothers under 21 years old, and over 3\% since 2008 among mothers who were unskilled workers or housewives. Second, the differences in prevalence of underweight at birth among maternal and foetal categories persisted or even increased from 2008.

[FIGURES 2 to 6]

\section{[TABLE I]}

Finally, Table II and III show the odds ratio (OR) and 95\% confidence intervals (95\% CI) of the crude and adjusted logistic binomial regressions performed for evaluating the impact of each of the three economic variables: Year-on-year GDP growth (per capita), Year-on-year Household Income (per capita) and Gini coefficient on underweight at birth. In the first three crude models performed (Table II), all economic indicators were significantly associated with the risk of underweight at birth, such that year-on-year economic improvement at national and household levels, as well as a decrease in income inequalities reduce the risk of underweight at birth. Table III shows the results of the model including the three economic variables adjusted by maternal and foetal covariates. In this model, only year-on-year GDP per capita remains predictive of underweight at birth $(\mathrm{OR}=0.991 ; 95 \% \mathrm{CI}=0.986-0.995)$, such that a reduction of one year-on-year percentage point in GDP increases by $0.90 \%$ the risk of being born with underweight at birth. Table III also allows an evaluation of the adjusted association of the maternal and foetal variables included in Table I and underweight at birth. Categories of reference were those with lower prevalence of underweight at birth in 
2003-2012: professional, 28-34 years old, multiparous and rural mothers, and female newborns. Maternal age showed a "U" shaped relationship with underweight at birth, with a higher risk of underweight at birth among newborns of mothers under 20 years old and over 34 years old compared with 28-34 year old mothers. The risk of being born with underweight at birth increased significantly compared with professionals as the quality of maternal employment decreased, being higher among newborns of unskilled $(\mathrm{OR}=1.331 ; 95 \% \quad \mathrm{CI}=1.260-1.364)$ workers and housewives $(\mathrm{OR}=1.369 ; 95 \%$ $\mathrm{CI}=1.332-1.408$ ); student mothers being the only group showing no significant differences with highly qualified mothers. Finally, the odds of underweight at birth increased as size of place of residence of the mother increased to over 10000 inhabitants when compared with newborns in rural areas and small towns.

[TABLE II]

[TABLE III]

\section{Discussion}

The present study attempts to detect the impact of the current financial crisis on the foetal development and birth outcome of neonates born in Spain between 2003 and 2012. With this aim, we have evaluated the temporal change and intra-population variability of underweight at birth in singleton term neonates of Spanish mothers as an indicator of intrauterine growth restriction, calculated separately for both sexes and term newborns according to the WHO Child Growth Standards (WHO, 2006b). Results have shown a sharp increase in the first years of the economic crisis (Figure 1). Certainly, the global prevalence of underweight at birth increased during the period of economic growth before the crisis, from 2.12\% in 2003 to 2.44 in 2007, an increase of $15.09 \%$ in a five-year period. However, the prevalence of underweight at birth increased $12.87 \%$ between 2007 and 2008 alone, from a prevalence of 2.33\% to 2.63\% (see Table I in the Appendix). Underweight at birth prevalence remained stable at around 2.6\% during the first five years of economic crisis. More relevant, this trend is shown by all maternal and foetal categories considered (Figures 2 to 7), even those with the least prevalence before the crisis, in particular, female newborns and newborns of multiparous mothers. The intrapopulation differences in the prevalence of underweight at birth preceding the onset of the economic crisis increased from 2008 onwards. We have performed a 
sensitivity analysis (Youden Index) to find a cut-off point in the temporal trend of prevalence of underweight at birth. As predicted, the sensitivity analysis establishes a threshold in 2007-2008, coinciding with the onset of the international economic crisis. These results could be explained at two levels: first, at a population level, the crisis might determine changes in the socio-demographic profile of women that become mothers, with an increasing predominance of mothers at higher gestational or obstetrical risk; and second, at an individual level, the crisis might affect foetal development and birth outcome through direct worsening of living conditions and increased maternal stress during pregnancy. Although the Spanish birth certificates analysed here offer no information for evaluating maternal stress levels or socioeconomic situations aside from employment, results provide several clues for both possibilities.

The immediate consequence of the economic crisis in Spain was a decrease in birth rate, which fell by 18.1\% between 2007 and 2013 (INE, 2015). Both national and immigrant women have reduced their fertility from 2008 onwards, reversing of the increasing contribution that immigrant births have made since the middle of the nineties (from $3.1 \%$ in 1996 to a maximum of $21.0 \%$ in 2008: National Statistics Institute, 2015). Among the Spanish mothers, the economic crisis is also accelerating pre-crisis trends in the socio-demographic profile of women who become mothers, specifically in relation to their age and occupation. Throughout the XXI Century, Spanish mothers have predominately become primiparous with an increasing mean age at first maternity (and mean age at maternity), reaching 31.06 years old in 2014 (INE, 2015). Delayed maternity, especially if associated with primiparity, increases the risk of negative pregnancy outcomes as well as of obstetric intervention, as our analysis of Spanish hospital data has confirmed (Bernis et al., 2013). Bernis and Varea (2013) considered that the reduction in mean birth weight in descendants of Spanish mothers described before the crisis was the consequence of changes in the distribution of gestational age among term newborns, with a significant increase in births born at 37 and 38 weeks, and a decrease in those born at $\geq 39$ weeks. Similar changes in the distribution of gestational age at birth in other developed (Davidoff et al., 2006), and developing (Murta et al., 2006), countries have been explained by an increase in obstetric interventionism (induced vaginal deliveries or Caesarean sections) originally intended to reduce foetal distress and mortality but currently extensively used in low-risk deliveries (Joseph et al., 2002). These trends of an increasing contribution of risk profile women, and high and growing obstetric interventionism have been proposed to explain the rises in 
prematurity and LBW rates described in European countries before the crisis (OECD, 2012; EURO-PERISTAT Project with SCPE and EUROCAT, 2013), and may also be contributing to the increasing incidence of underweight at birth both before and during the crisis. Certainly, our results showed that the prevalence and adjusted risk of being born with underweight maintained a " $U$ " shaped curve with maternal age, with extreme ages of motherhood (adolescents and those over 34) being associated with adverse outcomes of pregnancy, as also occurs among primiparous mothers when compared with those who are multiparous. All births considered, during the period analysed here, the category of Spanish mothers over 34 years old increased from 28.86\% in 2003-2007 to $36.62 \%$ in $2008-2012\left(\chi^{2}=27847.624, \mathrm{df}=3, \mathrm{p}<0.001\right)$. But on the other hand, Spanish mothers are actually mainly qualified women, a profile which is correlated with greater stability and resources, and maternal education, which affects birth outcome more clearly than employment (Voigt et al. 2014), perhaps through better prenatal care (Nastis and Crocker, 2012). Although very discreetly, from 2008 onwards primiparity reversed the rising trend it had maintained during the previous decade (from 54.93\% in to $52.69 \%$ in $2012: \chi^{2}=3167.499, \mathrm{df}=1, \mathrm{p}<0.001$ ), perhaps as a consequence of the growing contribution of wealthy women to national childbearing, who are now the predominant group among multiparous mothers. In summary, the economic crisis is strengthening previous trends that may have both positive and negative effects on birth outcome.

Yet, the economic crisis could also affect birth outcomes both directly (through worsening living conditions and reduced access to health and social services) and indirectly (through increased stress and lower self-esteem), both pathways contributing to an increased risk of harmful behaviours (Rutter and Quine, 1990). The Spanish birth certificate of the period analysed here offers no information for evaluating maternal socioeconomic circumstances or stress levels, aside from employment. We have incorporated in the analyses exogenous economic indicators associated with each birth. In the crude logistic regression models performed to assess the possible impact of the economic crisis on birth outcome (Table II), the three macroeconomic indicators selected were all significantly associated with the risk of being born underweight. However, in the fully adjusted model only GDP per capita remained a significant risk factor for underweight at birth among the economic indicators (Table III). The fact that the significant association between GDP per capita and risk of underweight at birth remained in the fully adjusted model seems to indicate an early and widespread impact 
of the economic crisis from its onset. Year-on-year regional Gross Disposable Income of Households per capita and Gini coefficient lost their predictive value on the dependent variable, the risk of being born with underweight. Both economic indicators are exogenous variables (regional and national levels, respectively) associated to each birth, and probably their inclusion in the adjusted model of the individual maternal variables better captures socioeconomic differences and their possible impact on birth outcome, particularly maternal employment. Certainly, maternal employment status should better express the direct impact of the economic crisis than macroeconomic indicators through worsening living conditions and psychological impact, particularly among pregnant women belonging to the most disadvantaged segments of society. Quality of employment expresses social differences in qualifications (educational level) and income, which are in turn determining factors of differences in access to health and social resources. Dooley and Prause (2005) described that, after adjusting for gestational age and maternal weight gain, maternal employment deterioration in American women was significantly associated with a decrease in birth weight through reduced intrauterine growth. Compared with the mothers of highest employment status (professionals), the ORs of underweight at birth increased as working conditions (stability and qualification) worsened. However, the highest OR was observed among housewives, probably most of them unemployed women, as the Spanish birth certificate does not include this category in the questionnaire to fill in. Thus, the relative increase in the prevalence of underweight at birth among newborns of unskilled workers and housewives - the maternal categories that also had the highest pre-crisis prevalencewas almost twice (around 20\%) that among those of the professional women. Housewives maintained an incidence and a risk of underweight at birth as high as those of the less favourable employment categories, as they are usually in charge of managing the family budget and have to face up to the deterioration of the domestic economy caused by recession (UCL Institute of Health Equity, 2012). In contrast, students were the only occupational group showing no significant differences with professional mothers in the risk of delivering underweight babies. This group of mothers might be less affected by stress as they are not in regular employment and have alternative sources of economic support, despite being very young mothers (mean age of 22.93 years old, $n=26034$, $s d=5.04)$.

The prevalence of underweight at birth increased in all maternal and foetal categories from 2008 onwards, even in those with the least prevalence before. For example, the 
absolute prevalence and adjusted risk of underweight at birth was always greater for male neonates than for females, an effect that is often ascribed to the greater sensitivity of males to environmental conditions (Stinson, 1985); however, the prevalence of underweight at birth increased in both sexes between 2003-2007 and 2008-2012 periods, even more so in female (19.61\%) than in male (16.03\%) newborns (see Table I Appendix). The same is true for parity-with a similar increase (over 16\%) for newborns of primiparous and multiparous mothers. These examples highlight a generalised and acute impact of the economic crisis on Spanish society. Similar findings were described by Astell-Burt and Feng (2013) in the United Kingdom, probably as a result of the stress caused by increased social and job insecurity as Catalano et al. (2011) suggest. After a period of economic prosperity, from 2008 onwards the Spanish population has undergone an unexpected and extended period of psychological uncertainty affecting almost all social sectors, irrespective of any immediate or substantive decline in living conditions (Ortega, 2012; Banco de España, 2014). Birth outcome is associated with perceived rather than objective stressful life events (Hedegaard et al., 1996), and the wide and immediate increase in underweight at birth may be expressing this psychological effect of the economic crisis on gestation before any material impact among mothers belonging to the most vulnerable sectors.

Recent reviews examining, at the aggregate-level, the effects of psychosocial stress on the risk of negative perinatal outcomes (low birth weight and preterm deliveries) generated results that remain inconclusive due to methodological discrepancies (Catalano et al., 2011; Littleton et al., 2010; Zilko, 2010). Nevertheless, individual-level studies have documented the association between birth outcomes and maternal psychological stress, ranging from chronic anxiety and depressive symptoms to acute stressors, and determined by both pregnancy-specific and general life event anxiety (Mulder et al., 2002; Torche, 2011). Potential pathways through which the experience of psychosocial stress by the mother may lead to negative perinatal outcomes have been proposed. Duthie and Reynolds (2013) reviewed emerging data from human studies linking lower birth weight and shorter gestational age at delivery with dys-regulation of the maternal hypothalamic-pituitary-adrenal (HPA) axis (i.e., increased transfer of glucocorticoids from mother to foetus). The impact of maternal stress on birth outcome may also operate indirectly on birth outcomes through increased negative health practices such as addictive behaviours, reduced antenatal care, and unhealthy or insufficient maternal nutrition (Sheehan, 1998). Placental corticotrophin-releasing 
hormone CRH secretion is stimulated by the maternal pituitary-adrenal stress hormones ACTH, beta-endorphin, and cortisol (Wadhwa et al., 1997). The prevalence of preterm deliveries is clearly associated with maternal stress through increased levels of maternal plasma concentrations of $\mathrm{CRH}$, which is involved in the timing of parturition (see the revision by Wadhwa et al., 2011).

In contrast, studies on the association between maternal exposure to stressors and birth weight have yielded mixed results, the relationship being stronger when multiple exposures interact to affect foetal growth (Paarlberg et al., 1993). Based on their own analysis of Brazilian women and other studies, Rondó et al. (2003) concluded that maternal stress affects birth weight by shortening gestational age, but does not determine intrauterine growth restriction (IUGR). Other studies (e.g., Evans et al., 2007) considered that the direct impact of maternal stress on birth weight disappears after controlling for confounding factors (unhealthy behaviours). Maternal stress has been considered the most important determinant of gestational length (and prevalence of preterm deliveries and LBW) in the first trimester of gestation, while foetal growth (and the prevalence of intrauterine growth restriction) depends more on resources and material conditions - particularly maternal nutrition —in the third trimester (Bozzoli and Quinta-Domeque, 2014). According to this hypothesis, maternal physiology would dampen the negative consequences of stress as pregnancy progresses, with little impact in the final stage of pregnancy (de Weeth and Buitelaar, 2005). However, studies analysing the stage of gestation at which stress is more critical have generated inconsistent and somewhat equivocal results (Eskenazi et al., 2007). Levels of maternal plasma CRH in the early part of the third trimester of pregnancy were also significantly associated with intrauterine growth restriction at term after controlling for the effects of other obstetric risk factors associated with IUGR (Wadhwa et al., 2004). In addition, results from Henrichs et al. (2010) suggested that the impact of maternal stress on foetal growth is even stronger in the last trimester of pregnancy, when foetal growth is essentially affected more by maternal and intrauterine environments than by genetic factors (Styne, 1998; WHO, 2006a). These results seem to confirm that maternal stress affects not only the physiology of parturition but also foetal growth and maturation, probably by compromised uteroplacental perfusion (Teixeira et al., 1999) and excessive foetal exposure to maternal glucocorticoids (Challis et al., 2001). 
Further analysis should clarify why the economic crisis in Spain is affecting maternal conditions and gestation by reducing weight at birth—as our results seem to confirmbut not timing of birth, as could be expected considering that the economic recession was affecting maternal conditions and birth outcomes in both ways and in different stages of gestation. Kramer (1987) stated that determinants of preterm birth and foetal growth retardation are different, and Wadhwa et al. (2004) have proposed that increased levels of maternal plasma concentrations of CRH determined by maternal stress have separate and distinct roles in processes related to the timing of delivery and foetal growth depending on the chronicity of the stressor.

\section{Conclusions}

In this article we have analysed one aspect of the so-called "biology of social adversity" (Boyce et al., 2012), the possible impact of the current international economic crisis on foetal development in Spain, by analysing secular trends and intrapopulation variability in underweight at birth. We used a very stringent marker of intrauterine growth restriction, including only term singleton newborns with birth weights under the $3^{\text {rd }}$ percentile (Usher and McLean, 1969). Our conclusion is that the greater increase in the prevalence and risk of underweight at birth since 2008 compared with the previous period of economic growth, and in all maternal and foetal categories analysed, confirm the widespread impact of economic recession on Spanish society, which cannot be explained just as a continuation of pre-crisis trends in reproductive behaviour and maternal profile. Social and economic inequalities in poor pregnancy outcomes persisted in Spain in the years preceding the economic crisis (García-Subirats et al., 2012), and it was to be expected that the current situation had widened this gap. This impact probably occurs through the combination of increased psychosocial stress-even in the better-off strata-and worsening socioeconomic conditions, although our data do not allow us to go further into the mechanisms affecting maternal environment and birth outcomes, as the information offered by the Spanish birth certificate is limited. Furthermore, we are also aware that analyses undertaken and their results can only demonstrate an association (not directionality or causality) between socioeconomic factors and birth outcomes in Spain. Further population studies which collect detailed information about epigenetic and metabolic modifications, as well as a wider range of maternal characteristics, social factors and subjective perceptions of women who have given birth will allow us to confirm the impact of the crisis on foetal development 
suggested by our results, and the mechanisms operating therein. Meanwhile, there is already clear evidence that the impact of the economic crisis on the European populations is modulated by the degree of social development and cohesion of the country, and by the governmental policies adopted in response to the crisis and preserve public welfare (Kaplan, 2012; Karanikolos et al., 2013; Suhrcke et al., 2009). Studies have confirmed that adequate emotional and social support during pregnancy acts as a buffer of the material and psychological impact of adverse economic conditions on foetal growth (Aarts and Vingerhoets, 1993; Hoffman and Hatch, 1996; Feldman et al., 2000; Da Costa et al., 2000), even more efficiently than resources (Rini et al., 1999).

The results seem to point to a worsening of maternal and gestational conditions with wide impact and the potential for long-term consequences. According to the "foetal programming hypothesis” (Barker, 1998), adverse living conditions of pregnant women, both material and psychological, have enduring consequences on foetal growth as well as persisting and long-term consequences later in life due to permanent changes in utero in the vascular, metabolic and endocrine systems. Moreover, evidence of a significant intergenerational effect of a negative exposure in utero have emerged over the last 25 years (Cameron, 1996). Especially in times of crisis, the consideration by WHO (2006a: 9-10) should be remembered: "By taking steps to promote optimal foetal development, it should be possible to improve outcomes not just for early survival but also for later survival, morbidity and other measures of human capital, which in turn, will lead to improved social and economic health and well-being. In other words, investment in the ability of all mothers to carry a healthy pregnancy will not only have immediate personal and social benefit, but also cumulative benefit for personal and social health and development over many decades.” 


\section{References}

Aizer A, Currie J. 2014. The intergenerational transmission of inequality: maternal disadvantage and health at birth. Science. 344:856-861.

Agudelo-Suárez AA, Ronda E, Vázquez-Navarrete ML, García AM, Martínez JM, Benavides FG. 2013. Impact of economic crisis on mental health of migrant workers: what happened with migrants who came to Spain to work? Int J Public Health. 58:627-631

Aarst MCG, Vingerhoets AJJM. 1993. Psychosocial factors and intrauterine fetal growth: a prospective study. J Psychosom Obstet Gynecol. 14:249-258.

Ásgeirsdóttir TL, Corman H, Noonan K, Ólafsdóttir P, Reichman NE. 2014. Was the economic crisis of 2008 good for Icelanders? Impact on health behaviors. Econ Hum Biol. 13:1-19.

Astell-Burt T, Feng X. 2013. Health and the 2008 economic recession: evidence from the United Kingdom. PLoS One. 8:e56674.

Banco de España. 2014. Informe anual 2013. Madrid, Publicaciones del Banco de España.

Barbaglia MG, Have M, Dorsselaer S, Alonso J, de Graaf R. 2014. Negative socioeconomic changes and mental disorders: a longitudinal study. $J$ Epidemiol Community Health. 69:55-62.

Barker DJ. 1998. In utero programming of chronic disease. Clin Sci (London). 95:115128.

Barker DJ, Eriksson JG, Forsén T, Osmond C. 2002. Fetal origins of adult disease: strength of effects and biological basis. Int J Epidemiol. 31:1235-1239.

Bartoll X, Palència L, Malmusi D, Suhrcke M, Borrell C. 2014. The evolution of mental health in Spain during the economic crisis. Eur J Public Health. 24:415-418.

Bernis C, Varea C. 2013. Pregnancy and delivery in Spanish and migrant women: An ecological approach. Anthropological Review. 76:129-150.

Bernis C, Varea C, Bogin B, González-González A. 2013. Labor management and mode of delivery among migrant and Spanish women: does the variability reflect differences in obstetric decisions according to ethnic origin? Matern Child Health J. 17:918-927.

Borrell C, Rodríguez-Sanz M, Bartoll X, Malmusi D, Novoa AM. 2014. El sufrimiento de la población en la crisis económica del Estado español. Salud Colect. 10:95-98. 
Boyce WT, Sokolowski MB, Robinson GE. 2012. Toward a new biology of social adversity. Proc Natl Acad Sci USA.109:17143-17148.

Bozzoli C, Quinta-Domeque C. 2014. The weight of the crisis: evidence from newborns in Argentina. Rev Econ Stat. 96:550-562.

Cameron N. 1996. Antental and birth factors and their relationship to child growth. In: Henry CJK and Ulijaszek SJ, editors. Long-term consequences of early environmental growth: growth, development and the lifespan development perspective, Society for the Study of Human Biology Symposium Series: Cambridge University Press. 69-90. Carolan-Olah M, Barry M. 2014. Antenatal stress: an Irish case study. Midwifery. 30:310-316.

Catalano R., Goldman-Mellor S, Saxton K, Margerison-Zilko C, Subbaraman M, LeWinn K, Anderson E. 2011. The health effects of economic decline. Annu Rev Public Health. 32:431-450.

Cervero-Liceras F, McKee M, Legido-Quigley H. 2015. The effects of the financial crisis and austerity measures on the Spanish health care system: a qualitative analysis of health professionals' perceptions in the region of Valencia. Health Policy. 119:100-106. Challis JR, Sloboda D, Matthews SG, Holloway A, Alfaidy N, Patel FA, Whittle W, Fraser M, Moss TJ, Newnham J. 2001. The fetal placental hypothalamic-pituitaryadrenal (HPA) axis, parturition and post natal health. Mol Cell Endocrinol. 185:135144.

Cooper B. 2011. Economic recession and mental health: an overview. Neuropsychiatr. 25:113-117.

Da Costa D, Dritsa M, Larouche J, Brender W. 2000. Psychosocial predictors of labor/delivery complications and infant birth weight: a prospective multivariate study. $J$ Psychosom Obstet Gynaecol. 21:137-148.

Datta Gupta N, Deding M, Lausten M. 2013. The effect of low birth weight on height, weight and behavioral outcomes in the medium-run. Econ Hum Biol. 11:42-55.

Davidoff MJ, Dias T, Damus K, Russell R, Bettegowda VR, Dolan S, Schwarz RH, Green NS, Petrini J. 2006. Changes in the gestational age distribution among U.S. singleton births: Impact on rates of late preterm birth, 1992 to 2002. Semin Perinatol. 30:8-15.

De Onís M, Onyango A, Borghi E, Siyam A, Blössner M, Lutter C; WHO Multicentre Growth Reference Study Group. 2012. Worldwide implementation of the WHO Child Growth Standards. Public Health Nutr. 15:1603-1610. 
De Vogli R, Marmot M, Stuckler D. 2013. Excess suicides and attempted suicides in Italy attributable to the great recession. J Epidemiol Community Health. 67:378-379. De Weerth C, Buitelaar JK. 2005. Physiological stress reactivity in human pregnancya review. Neurosci Biobehav Rev. 29:295-312.

Dooley D, Prause J. 2005. Birth weight and mothers' adverse employment change. $J$ Health Soc Behav. 46:141-155.

Duthie L, Reynolds RM. 2013. Changes in the maternal hypothalamic-pituitary-adrenal axis in pregnancy and postpartum: Influences on maternal and fetal outcomes.

Neuroendocrinology. 98:106-115.

Eskenazi B, Marks AR, Catalano R, Bruckner T, Toniolo PG. 2007. Low

birthweight in New York City and upstate New York following the events of September 11th. Hum Reprod. 22:3013-3020.

EURO-PERISTAT Project. 2013. European Perinatal Health Report. The health and care of pregnant women and babies in Europe in 2010. Paris, Euro-Peristat.

EUROSTAT. 2014. Living conditions in Europe. Luxembourg, Publications Office of the European Union.

Eutostat. 2015. Eurostat, European Union. Available online at http://ec.europa.eu/eurostat/data/database, accessed 27 August 2015.

Evans J, Heron J, Patel RR, Wiles N. 2007. Depressive symptoms during pregnancy and low birth weight at term: longitudinal study. Br J Psychiatry. 191:84-85.

Feldman PJ, Dunkel-Schetter C, Sandman CA, Sandman CA, Wadhwa PD. 2000.

Maternal social support predicts birth weight and fetal growth in human pregnancy.

Psychosom Med. 62:715-725.

Fuster V, Zuluaga P, Colantonio SE, Román-Busto J. 2013. Factors determining the variation in birth weight in Spain (1980-2010). Ann Hum Biol. 40:266-275.

García-Subirats I, Pérez G, Rodríguez-Sanz M, Ruiz-Muñoz D, Salvador J. 2012.

Neighborhood inequalities in adverse pregnancy outcomes in an urban setting in Spain: a multilevel approach. J Urban Health. 89:447-463.

Gili M, Roca M, Basu S, McKee M, Stuckler D. 2013. The mental health risks of economic crisis in Spain: evidence from primary care centers, 2006 and 2010. Eur J Public Health. 23:103-108.

Gluckman PD, Hanson MA, Cooper C, Thornburg KL. 2008. Effect of in utero and early-life conditions on adult health and disease. N Engl J Med. 359:61-73.

Goldenberg R, Cliver S. 1997. Small for Gestational Age and Intrauterine Growth Restriction: Definitions and Standards. Clin Obstet Gynecol. 40:704-714. 
Hedegaard M, Henriksen TB, Sabroe S, Secher NJ. 1996. The relationship between psychological distress during pregnancy and birth weight for gestational age. Acta Obstet Gynecol Scand. 75:32-39.

Henrichs J, Schenk JJ, Roza SJ, van den Berg MP, Schmidt HG, Steegers EA, Hofman A, Jaddoe VW, Verhulst FC, Tiemeier H. 2010. Maternal psychological distress and fetal growth trajectories: the Generation R Study. Psychol Med. 40:633-643. Hoffman S, Hatch C. 1996. Stress, social support and pregnancy outcome: a reassessment based on recent research. Paediatr Perinat Epidemiol. 10:380-405. INE. 2015. Madrid Instituto Nacional de Estadística (National Statistics Institute, Spain). Available online at: http://www.ine.es/en/inebmenu/indice_en.htm, and http://www.ine.es/en/prensa/seccion_prensa_en.htm, accessed 27 August 2015. Joseph KS, Demissie K, Kramer MS. 2002. Obstetric intervention, stillbirth, and preterm birth. Semin Perinatol. 26:250-259.

Juárez S, Alonso Ortíz T, Ramiro-Fariñas D, Bolúmar F. 2012. The quality of vital statistics for studying perinatal health: the Spanish case. Paediatr Perinat Epidemiol. 26:310-315.

Juárez S, Revuelta-Eugercios BA, Ramiro-Fariñas D, Viciana-Fernández F. 2014. Maternal education and perinatal outcomes among Spanish women residing in southern Spain (2001-2011). Matern Child Health J. 18:1814-1822.

Kaplan GA. 2012. Economic crises: Some thoughts on why, when and where they (might) matter for health. A tale of three countries. Soc Sci Med. 74:643-646.

Karanikolos M, Mladovsky P, Cylus J, Thomson S, Basu S, Stuckler D, Mackenbach JP, McKee M. 2013. Financial crisis, austerity, and health in Europe. Lancet. 381:13231331.

Kogan MD. 1995. Social causes of low birth weight. J R Soc Med. 88:611-615.

Kramer MS. 1987. Determinants of low birth weight: methodological assessment and meta-analysis. Bull World Health Organ. 65:663-737.

Kramer MS, Séguin L, Lydon J, Goulet L. 2000. Socio-economic disparities in pregnancy outcome: why do the poor fare so poorly? Paediatr Perinat Epidemiol. 14:194-210.

Fundación BBVA. 2015. Servicios públicos, diferencias territoriales e igualdad de oportunidades. Valencia, Fundación BBVA-IVIE.

Lampl M, Gotsch F, Kusanovic JP, Gomez R, Nien JK, Frongillo EA, Romero R. 2010. Sex differences in fetal growth responses to maternal height and weight. Am J Hum Biol. 22:431-443. 
Legido-Quigley H, Urdaneta E, González A, La Parra D, Muntaner C, Álvarez-Dardet C, Martín-Moreno JM, McKee M. 2013. Erosion of universal health coverage in Spain. Lancet. 382:1977.

Littleton HL, Bye K, Buck K, Amacker A. 2010. Psychosocial stress during pregnancy and perinatal outcomes: a meta-analytic review. J Psychosom Obstet Gynaecol. 31:219228.

Llano-Ortiz JC. 2015. El estado de la pobreza, cuarto informe. Seguimiento del indicador de riesgo de pobreza y exclusión social en España 2009-2013. Madrid, European Anti Poverty Network (EAPN) España.

López-Bernal JA, Gasparrini A, Artundo CM, McKee M. 2013. The effect of the late 2000s financial crisis on suicides in Spain: an interrupted time-series analysis. Eur $J$ Public Health. 23:732-736.

Maynou L, Saez M, Lopez-Casasnovas G. 2014. Has the economic crisis widened the intraurban socioeconomic inequalities in mortality? The case of Barcelona, Spain. $J$ Epidemiol Community Health.

McIntire DD, Bloom SL, Casey BM, Leveno KJ. 1999. Birthweight in relation to morbidity and mortality among newborn infants. N Eng J Med. 340:1234-1238.

Méndez R, Abad LD, Echaves C. 2015. Atlas de la crisis. Impactos socioeconómicos y territorios vulnerables en España. Valencia, Tirant lo Blanch.

Ministerio de Economía y Hacienda. 2007. Revisión de la metodología para el cálculo de los indicadores sintéticos de la economía española. Madrid, Ministerio de Economía y Hacienda, Dirección General de Política Económica Subdirección General de Análisis Macroeconómico.

Ministerio de Hacienda y Administraciones Públicas. 2013. Avance de la actuación económica y financiera de las Administraciones públicas 2013. Madrid, Ministerio de Hacienda y Administraciones Públicas.

Ministerio de Sanidad, Servicios Sociales e Igualdad. 2012. Sistema Nacional de Salud. España 2012. Madrid, Ministerio de Sanidad, Servicios Sociales e Igualdad.

Miret M, Caballero FF, Huerta-Ramírez R, Moneta MV, Olaya B, Chatterji S, Haro JM, Ayuso-Mateos JL. 2014. Factors associated with suicidal ideation and attempts in Spain for different age groups. Prevalence before and after the onset of the economic crisis. J Affect Disord. 163:1-9.

Mulder EJ, Robles de Medina PG, Huizink AC, Van den Bergh BR, Buitelaar JK, Visser GH. 2002. Prenatal maternal stress: effects on pregnancy and the (unborn) child. Early Hum Dev. 70:3-14. 
Murta EF, Freire GC, Fabri DC, Fabri RH. 2006. Could elective cesarean sections influence the birth weight of full-term infants? Sao Paulo Med J. 124:313-315. Nastis SA, Crocker TD. 2012. Valuing mother and child health: the intrauterine environment. Econ Hum Biol. 10:318-328.

OECD. 2012. Health at a Glance: Europe 2012. Europe, OECD publishing. OECD. 2014. Society at a Glance 2014. OECD Social Indicators. Europe, OECD publishing.

OECD. 2015. In It Together: Why Less Inequality Benefits All. Overview of inequality trends, key findings and policy directions. Europe, OECD publishing.

Ortega E, Peñalosa J. 2012. Claves de la crisis económica española y retos para crecer en la UEM. Madrid, Unidad de publicaciones del Banco de España.

Paarlberg KM, Vingerhoets AJ, Passchier J, Dekker GA, Van Geijn HP. 1993.

Psychosocial factors and pregnancy outcome: a review with emphasis on methodological issues. J Psychosom Res. 39:563-595.

Rajmil L, Medina-Bustos A, Fernández de Sanmamed MJ, Mompart-Penina A. 2013. Impact of the economic crisis on children's health in Catalonia: a before-after approach. BMJ Open. 3:e003286.

Rini CK, Dunkel-Schetter C, Wadhwa PD, Sandman CA. 1999. Psychological adaptation and birth outcomes: the role of personal resources, stress, and sociocultural context in pregnancy. Health Psychol. 18:333-345.

Río I, Castelló A, Jané N, Prats R, Barona C, Más R, Rebagliato M, Zurriaga O, Bolúmar F. 2010. Calidad de los datos utilizados para el cálculo de indicadores de salud reproductiva y perinatal en población autóctona e inmigrante. Gac Sanit. 24:172-177. Robert G, Martínez JM, García AM, Benavides F, Ronda E. 2014. From the boom to the crisis: changes in employment conditions of immigrants in Spain and their effects on mental health. Eur J Public Health. 24:404-409.

Rondó P, Ferreira RF, Nogueira F, Ribeiro MC, Lobert H, Artes R. 2003. Maternal psychological stress and distress as predictors of low birth weight, prematurity and intrauterine growth retardation. Eur J Clin Nutr. 57:266-272.

Rutter DR, Quine L. 1990. Inequalities in pregnancy outcome: a review of psychosocial and behavioural mediators. Soc Sci Med. 30:553-568.

Suhrcke M, Stuckler D, Leone T. 2009. Recession and health in Europe: what to expect? London, London School of Economics and Policital Science.

Spencer N. 2003. Social, Economic, and Political Determinants of Child Health. Pediatrics. 112:704-706. 
Sheehan TJ. 1998. Stress and low birth weight: a structural modeling approach using real life stressors. Soc Sci Med. 47:1503-1512.

Spong CY. 2013. Defining "term" pregnancy: recommendations from the Defining "Term" Pregnancy Workgroup. JAMA. 309:2445-2446.

Stinson S. 1985. Sex differences in environmental sensitivity during growth and development. Yearb Phys Anthropol. 28:123-147.

Stuckler D, Basu S, Suhrcke M, Couts A, McKee M. 2009. The public health effect of economic crises and alternative policy responses in Europe: an empirical analysis. Lancet. 374:315-323.

Styne DM. 1998. Fetal growth. Clin Perinatol. 25:917-938.

Teixeira JM, Fisk NM, Glover V. 1999. Association between maternal anxiety in pregnancy and increased uterine artery resistance index: cohort based study. BMJ. 318:153-157.

Torche F. 2011. The effect of maternal stress on birth outcomes: exploiting a natural experiment. Demography. 48:1473-1491.

UCL Institute of Health Equity. 2012. UCL Institute of Health Equity for the London Health Inequalities Network. London: England.

UNICEF. 2014. La infancia en España 2014. El valor social de los niños: hacia un Pacto de Estado por la Infancia. Madrid, UNICEF Comité Español.

Usher R, McLean F. 1969. Intrauterine growth of live-born Caucasian infants at sea level: standards obtained from measurements in 7 dimensions of infants born between 25 and 44 weeks of gestation. J Pediatr. 74:901-910.

Van den Noord P, Székely IP. 2011. Economic crisis in Europe. Causes, consequences and responses. Routledge, London.

Varea C, Bernis C, González-González A. 2012. Maternal characteristics and temporal trends in birth outcomes: comparison between Spanish and migrant mothers. Int J Popul Res. 12:1-8.

Voigt M, Heineck G, Hesse V. 2004. The relationship between maternal characteristics, birth weight and pre-term delivery: evidence from Germany at the end of the 20th century. Econ Hum Biol. 2:265-280.

Vlachadis N, Kornarou E. 2013. Increase in stillbirths in Greece is linked to the economic crisis. BMJ. 346:f1061.

Wadhwa PD, Sandman CA, Chicz-DeMet A, Porto M. 1997. Placental CRH modulates maternal pituitary adrenal function in human pregnancy. Ann N Y Acad Sci. 814:276281. 
Wadhwa PD, Garite TJ, Porto M, Glynn L, Chicz-DeMet A, Dunkel-Schetter C, Sandman CA. 2004. Placental corticotropin-releasing hormone (CRH), spontaneous preterm birth, and fetal growth restriction: A prospective investigation. Am J Obstet Gynecol. 191:1063-1069.

Wadhwa PD, Entringer S, Buss C, Lu MC. 2011. The contribution of maternal stress to preterm birth: issues and considerations. Clin Perinatol. 38:351-384.

Wollman HA. 1998. Intrauterine growth restriction: definition and etiology. Horm Res. 49:S1-S6.

Wood D. 2003. Effect of Child and Family Poverty on Child Health in the United States. Pediatrics. 112:707-711.

WHO. 2006a. Promoting optimal fetal development: report of a technical consultation. Geneva, Switzerland.

WHO. 2006b. WHO Child Growth Standards: length/height-for-age, weight-for-age, weight-for-length, weight-for-height and body mass index-for-age: Methods and Development. Geneva, Switzerland.

WHO. 2013. Health systems in times of global economic crisis: an update of the situation in the WHO European Region. Copenhagen, Denmark.

Wilcox AJ. 2001. On the importance-and the unimportance—of birthweight. Int J Epidemiol. 30:1233-1241.

Zeitlin J, Szamotulska K, Drewniak N, Mohangoo AD, Chalmers J, Sakkeus L, Irgens L, Gatt M, Gissler M, Blondel B, Euro-Peristat Preterm Study Group. 2013. Preterm birth time trends in Europe: a study of 19 countries. BJOG. 120:1356-1365.

Zhang J, Merialdi M, Platt LD, Kramer MS. 2010. Defining normal and abnormal fetal growth: promises and challenges. Am J Obstet Gynecol. 202:522-528.

Zilko C. 2010. Economic contraction and birth outcomes: an integrative review. Hum Reprod Update. 16:445-458. 